\title{
La industria financiera y los fondos inmobiliarios en Brasil: lógicas de inversión y dinámicas territoriales
}

\section{The financial industry and the real estate trusts in Brazil: investment logics and territorial dynamics}

DANIEL SANFELICI*

\begin{abstract}
Real estate investment trusts (REITs) recently gained prominence in commercial real estate investment in Brazil. This paper looks into REITs' growth with two basic aims. First, the regulatory and economic context that enabled their growth is explored. Second, the territorial implications of their investment decisions is considered. The paper's key finding is that the financial logic that underlies the creation of REITs explains, on the one hand, the instability that beset their growth cycle and, on the other, the territorial concentration of their investments.
\end{abstract}

Keywords: real estate investment trusts, financial markets, urban space, financialization, Brazil.

\section{Resumen}

Los fondos inmobiliarios han adquirido recientemente más importancia en la inversión inmobiliaria terciaria en Brasil. Este artículo examina el crecimiento de los fondos inmobiliarios atendiendo a dos objetivos: el primero consiste en aclarar el contexto que ha permitido el crecimiento de dichos vehículos; el segundo, examinar las repercusiones territoriales de las decisiones de inversión. Como conclusión, se sostiene que la lógica financiera que orienta la creación de los fondos inmobiliarios explica, por una parte, la inestabilidad que ha caracterizado el ciclo de ascensión de esos vehículos y, por otra, la concentración territorial de sus inversiones.

Palabras clave: fondos de inversión inmobiliaria, mercado financiero, espacio urbano, financiarización, Brasil.

* Universidad Federal Fluminense (Niterói, Rio de Janeiro, Brasil), correo-e: danielsanfelici@ gmail.com 


\section{Introducción}

Desde la década de 1980, entre las principales iniciativas de los gobiernos precursores de la reforma institucional del capitalismo fordista destaca la desregulamentación y liberalización de los mercados financieros, hasta entonces sometidos a una serie de normas que amparaban a los clientes bancarios y que restringían la libertad de circulación financiera en pro de la estabilidad macroeconómica y del encaminamiento del ahorro agregado hacia la acumulación industrial. Ante esos cambios regulatorios fue fundamental el crecimiento y consolidación de los fondos de pensiones y los vehículos de inversión colectiva como los fondos mutuos (mutual funds), que, gradualmente, fueron adquiriendo primacía sobre los depósitos bancarios como destino del ahorro de los hogares (Chesnais, 2002; Plihon, 2010; Orléan, 1999; Lapavitsas, 2009). El aumento progresivo del volumen de recursos, a disposición de esos agentes, generó una presión continua para la libertad de inversión financiera y la creación de nuevos activos financieros que se pudieran agregar a sus carteras de inversión (Leyshon y Thrift, 2007).

A partir de los últimos treinta años, el mercado de tierras y el sector inmobiliario constituyeron una de esas nuevas fronteras de inversión financiera al conectarse progresivamente con la dinámica del mercado de capitales por medio de mecanismos de securitización (o titulización) de activos y de numerosas innovaciones afines. La influencia ejercida por los mercados financieros sobre el destino del financiamiento habitacional, las políticas de renovación urbana, las características y la distribución geográfica de las inversiones inmobiliarias han sido objeto de una literatura en franca expansión (Coakley, 1994; Gotham, 2006; 2009; Shimbo, 2012; Fix, 2011; Botelho, 2007; Newman, 2009; Renard, 2008; Rolnik, 2013; Aalbers, 2008; Theurillat et al., 2010; Theurillat et al., 2015; Weber, 2010; David y Halbert, 2014; Halbert et al., 2014; Sanfelici, 2013a).

$\mathrm{Al}$ enfocar el crecimiento y la evolución de los fondos de inversión inmobiliaria en Brasil se pretende contribuir, con este artículo, a la elucidación de una de las dimensiones recientes de la articulación entre mercados financieros liberalizados y la producción de las ciudades, complementando estudios anteriores que realizamos sobre los grandes desarrolladores y su relación (conflictiva) con el mercado financiero (Sanfelici, 2013a; Sanfelici y Halbert, 2016).

Los objetivos principales que motivaron la investigación son: develar las fuerzas primarias que impulsaron el crecimiento y dinamización del mercado de fondos de inversión inmobiliaria en el periodo 2008-2014, cuando se identificó un ciclo de ascensión de las emisiones primarias de dichos vehículos que alcanzó su ápice en 2012; el siguiente fue analizar 
detenidamente las decisiones de inversión de los gestores de fondos, tanto desde el punto de vista del perfil de inmuebles como en cuanto a la ubicación de éstos a fin de arrojar luz sobre los patrones de desarrollo regional y urbano que dicho circuito de inversión ha ayudado a promover.

El artículo se divide en dos secciones principales: en la primera, se discute el contexto institucional y económico que creó las condiciones para el crecimiento de los fondos de inversión inmobiliaria en los últimos años, así como la inestabilidad que caracterizó el ciclo de ascensión de esos vehículos en el periodo estudiado. Se señala que los fondos de inversión inmobiliaria son producto de un ambiente regulatorio que se ha perfeccionado desde mediados del 2000, por medio de la normalización de la creación y la gestión de los fondos de inversión inmobiliaria, de la definición de las atribuciones de cada agente en ese circuito y de la concesión de incentivos tributarios a los inversores. Sin embargo, más allá de ese nuevo marco regulatorio, se resalta que el crecimiento de los fondos es la consecuencia de la implementación de estrategias de los agentes financieros especializados que sacaron provecho de esas mejoras regulatorias para divulgar y promover, entre sus clientes, los fondos de inversión inmobiliaria como alternativas seguras y rentables de diversificación de cartera. Esos mismos agentes son parte constitutiva del ciclo de expectativas optimistas que animó la emisión de un número creciente de nuevos fondos y generó una valorización de las cuotas entre 2012 y comienzos de 2013.

En la segunda parte del artículo se analizan las decisiones estratégicas de los gestores de fondos de inversión inmobiliaria a fin de comprender cómo las expectativas y percepciones dominantes en el mercado financiero influyeron en el perfil de los activos adquiridos y, por ende, contribuyeron a producir un patrón de desarrollo regional y urbano esencialmente concentrador, tanto en el ámbito del territorio nacional como a escala intraurbana.

Las conclusiones del artículo se fundamentan en una investigación realizada entre 2014 y 2015. Los procedimientos metodológicos, de naturaleza cualitativa, comprendieron tres etapas principales: la primera consistió en recabar datos e indicadores sobre el rendimiento operativo y financiero de los fondos de inversión inmobiliaria con cuotas negociadas en la Bolsa de Valores de São Paulo (Bovespa). Debido a que las cuotas de esos fondos se clasifican como títulos negociables, la información relativa a esos activos (informes a los inversores, balances financieros, prospectos de emisiones, etc.) debe registrarse ante la Comissão de Valores Mobiliários (Comisión de Títulos Negociables), el cual la divulga y la pone a disposición de quienes quieran consultarla. Asimismo, algunos datos se obtuvieron de informes de consultorías y en sitios web de fondos 
de inversión inmobiliaria, bancos de inversión y gestoras de activos financieros, estas últimas, responsables de la estructuración del fondo y distribución de las cuotas, o bien, de la gestión de los fondos (en algunos casos, de todas las etapas). Entre los datos obtenidos se incluyen, entre otras, la ubicación de los activos inmobiliarios pertenecientes a los fondos, dato que resultó esencial para producir la cartografía presentada.

La segunda etapa consistió en una investigación sistemática en periódicos y publicaciones especializadas en negocios (Exame, Valor, Istoé Dinheiro, Infomoney, etc), con el objetivo de profundizar en la comprensión de los factores determinantes del crecimiento de los fondos en el periodo seleccionado e identificar los principales agentes (individuos y empresas) de ese circuito de negocios. La tercera etapa consistió en la realización de 10 entrevistas semiestructuradas a gestores de fondos, profesionales del área de estructuración y distribución de fondos, consultores jurídicos del sector y analistas independientes, entre mayo y diciembre de 2014, en las ciudades de São Paulo y Río de Janeiro. Con las entrevistas se buscó complementar el material reunido en la primera etapa con informaciones más subjetivas, como las referidas a motivaciones, percepciones, expectativas de los agentes más directamente involucrados en el circuito de los fondos de inversión inmobiliaria, así como evidencias de cómo se elaboran las estrategias de esos agentes.

\section{Una nueva frontera en la interfaz de los mercados financieros con el mercado inmobiliario}

La dinámica del capitalismo a finales de 1970 se caracterizó por la centralidad cada vez mayor de los mercados financieros y de los agentes que operan en ese mercado. La liberalización y la desregulamentación financieras, iniciadas emblemáticamente por los gobiernos conservadores de Reagan y Thatcher y difundidas desde entonces como modelo para numerosos países, fortalecieron las tendencias de conversión de una fracción cada vez mayor del patrimonio de los hogares en riqueza financiera, ya sea directamente, por la propiedad de acciones y títulos financieros (es el caso de los estratos más ricos), o indirectamente, por medio de la participación en fondos de pensiones y otros instrumentos de inversión colectiva (más difundidos en estratos de ingreso medio).

Esas transformaciones tuvieron como consecuencia poner el mercado de capitales y su lógica de corto plazo en el puesto de comando de la dinámica económica: las finanzas no son actualmente sólo un sector entre los demás, cuya especificidad radicaría en su papel de intermediación entre ahorristas y empresas que demandan recursos para invertir; más bien, su lógica, prioridades y lenguaje condicionan cada vez más el modus 
operandi de las otras esferas de la actividad económica. Ese fenómeno es más notorio en la gestión de las empresas, pero influye también en las decisiones cotidianas de las familias (relativas al consumo y al ahorro) y la administración del gasto público (Froud et al., 2002; Orléan, 1999; Aglietta, 2004; Plihon, 2010; Lapavitsas, 2009).

La fuerte centralización del ahorro en entidades como fondos de pensiones y fondos mutuos estimuló, desde la década de 1980, una búsqueda incesante de nuevas inversiones financieras que pudieran componer la cartera de dichas entidades. Los bancos de inversión y gestoras de activos, directamente interesados en su calidad de intermediarios, fueron ágiles en encontrar nuevas formas de financiarización de la riqueza por medio de innovaciones como la securitización de activos y de ofertas públicas de acciones y títulos privados. Ese es el contexto que permite entender la evolución decisiva que alcanzó el segmento inmobiliario en muchos países: un sinfín de innovaciones financieras permitieron desarraigar el sector inmobiliario de sus condiciones estrictamente locales y convertir la propiedad inmobiliaria y la rentabilidad generada por esa propiedad en activos financieros homogeneizados, negociables en bolsas de valores y mercados mostrador o over-the-counter (Gotham, 2006; 2009), definidos por Harvey (1999) como una forma de capital ficticio. Esas innovaciones buscaron eliminar algunas de las barreras que hacían del inmobiliario un sector poco atractivo para los inversores financieros sobre todo la baja liquidez, la elevada opacidad y el valor unitario elevado de cada activo-, reservándolo para las élites locales que veían en la propiedad de los inmuebles un modo preferencial para la preservación del patrimonio acumulado.

Los fondos de inversión inmobiliaria se inscriben de forma inequívoca en esa tendencia de aproximación del sector inmobiliario a los mercados financieros liberalizados; ${ }^{1}$ en Brasil, su surgimiento y evolución ocurren en un contexto más amplio de cambios regulatorios e institucionales que permitieron la creación y negociación de activos financieros con rentabilidad basada en actividades inmobiliarias, como los Certificados de Recebiveis Imobiliários (CRI), ${ }^{2}$ las letras de crédito inmobiliario (LCI) y papeles (acciones y obligaciones), emitidos por constructoras, desarolladores y compañías inmobiliarias a partir de la década del 2000, en pos de

\footnotetext{
${ }^{1}$ Para un panorama del crecimiento y evolución global de los fondos de inversión inmobiliaria, llamados real estate investment trusts en los países anglófonos, aunque desde una perspectiva ortodoxa, ver Sotelo y McGreal (2013) y Lizieri (2009). En Boisnier (2015), también se presenta un panorama de esos vehículos para el caso francés.

${ }^{2}$ Títulos de crédito hipotecario negociables.
} 
un crecimiento significativo del volumen de activos negociados en la Bolsa de Valores de São Paulo. ${ }^{3}$

Sin embargo, aun siendo parte de ese movimiento más amplio, algunas particularidades de los fondos de inversión inmobiliaria - como un modelo de negocios diferente al adoptado por las firmas de desarrollo y el papel coordinador cumplido por las instituciones financieras en el montaje del negocio- ofrecen un ángulo diferenciado para observar las consecuencias de la articulación del segmento inmobiliario con los mercados financieros. Esa constatación también se ve reforzada por el hecho de que pocos estudios han abordado, hasta ahora, los fondos de inversión inmobiliaria con el objetivo de examinar detenidamente sus prácticas de negocios y cómo éstas repercuten en la dinámica territorial urbana (entre las excepciones están Botelho, 2007; Cattaneo Pineda, 2011; Boisnier, 2015).

Los fondos de inversión inmobiliaria, regulados en 1993 (Ley no 8668), son vehículos de inversión colectiva cuya finalidad es la inversión en activos de base inmobiliaria y la distribución periódica de las ganancias percibidas entre los poseedores de cuotas. Actualmente, en Brasil, las personas físicas que invierten en fondos de inversión inmobiliaria gozan de exoneración del impuesto a la renta, siempre y cuando el fondo atienda a los siguientes requisitos: 1 . el fondo debe tener, como mínimo, 50 poseedores de cuotas; 2. ningún poseedor de cuotas puede poseer $10 \%$ de las cuotas del fondo; 3. el fondo debe distribuir por lo menos $95 \%$ de la rentabilidad entre los poseedores de cuotas. ${ }^{4}$ Existen diferentes modalidades de fondos. Algunos se cotizan y negocian abiertamente en las bolsas de valores, mientras otros tan sólo en mercados mostrador (o sea, sus precios no se cotizan diariamente); algunos (la mayoría, actualmente) tienen como objetivo la inversión de los recursos recaudados de los inversores en inmuebles para fines de alquiler, mientras otros invierten su capital en otros activos financieros de base inmobiliaria (como los ya mencionados CRI) o participan en empresas de desarrollo inmobiliario por medio de sociedades limitadas, en cuyo caso se puede tener un plazo finito de operación, disolviéndose el fondo tras la conclusión del emprendimiento en cuyo financiamiento invirtió. ${ }^{5}$

Nos detendremos aquí exclusivamente en los fondos cotizados en la Bovespa que operan en el mercado de alquiler de inmuebles comerciales de oficinas. Se trata de instituciones financieras y, más particularmente, de bancos de inversión y de empresas gestoras de activos que actúan como intermediarias entre el inversor y las empresas que serán las usuarias fina-

\footnotetext{
${ }^{3}$ No es nuestro objetivo, aquí, describir todos esos cambios regulatorios, ya detallados en trabajos de otros autores. Ver, entre otros, Botelho (2007); Royer (2009); Fix (2011); Sanfelici (2013b).

${ }^{4}$ Estos requisitos tienen por objetivo inhibir la creación de fondos con fines puramente fiscales.

${ }^{5}$ Este es el caso del fondo inmobiliario Panamby, en São Paulo, estudiado por Botelho (2007).
} 
les de los inmuebles. Entre éstas se cuentan desde departamentos de inversión de grandes bancos comerciales (Itaú, Banco do Brasil, Caixa) hasta instituciones especializadas en finanzas estructuradas y gestión de activos (XP Investimentos, Oliveira Trust, Rio Bravo, Votorantim Asset, etc.).

Estas instituciones realizan tres operaciones básicas: la estructuración del fondo, o sea, el montaje del negocio con una proyección de flujo de caja y la elaboración de un prospecto con las informaciones básicas de la operación y las directrices estratégicas de la gestión; la distribución de las cuotas entre los inversores, que se puede realizar por oferta pública o restringida; la gestión del fondo, que incluye la prospección de locatarios; la realización de mejoras en los inmuebles (o propuestas de mejora cuando el inmueble forma parte de una propiedad horizontal); la elaboración y la supervisión de contrato de alquiler; la distribución de las ganancias entre los inversores; entre otras funciones (algunas, evidentemente, delegadas a otras empresas).

Desde el punto de vista de los inversores, el fondo inmobiliario encuentra su justificación, en primer lugar, en la movilidad que la liquidez otorga al capital invertido: si la reventa de un inmueble de inversión (por ejemplo, una sala comercial o un apartamento residencial adquiridos para obtener renta de alquiler) suele llevar algunas semanas o aun meses, revender una cuota de participación en un fondo de inversión inmobiliaria en la bolsa de valores no debería, al menos idealmente, demorar más que algunos días en el mercado secundario. Además, a diferencia de lo que ocurre cuando se es propietario de un inmueble físico, en el caso de las cuotas de fondos, los costos de transacción (como los relacionados a la transferencia de la propiedad) son relativamente bajos.

La segunda justificación, frecuentemente aducida, consiste en que la inversión en fondos de inversión inmobiliaria no exigiría la misma movilización de capital que la compra de un inmueble: las cuotas de fondos poseen un valor unitario modesto, lo que permitiría al pequeño inversor obtener un ingreso de base inmobiliaria sin necesitar desembolsar un monto muy elevado. Por último, una de las ventajas que se atribuyen más a menudo a los fondos se refiere a que éstos permiten moderar el riesgo de la inversión por medio de una política de diversificación de activos inmobiliarios. Según ese argumento, inspirado en la teoría moderna de selección de cartera de Markowitz, una cartera diversificada de inmuebles permitiría minimizar los riesgos asociados a la insolvencia de un locatario individual y a los largos periodos de vacancia, visto que las dificultades derivadas del alquiler de un inmueble podrían compensarse parcial o 
integralmente por las ganancias percibidas de los otros inmuebles que componen la cartera. ${ }^{6}$

Todas esas características ponen de manifiesto una creciente adecuación del sector inmobiliario a la lógica de corto plazo que prevalece en los mercados financieros: la decisión sobre poseer un título de base inmobiliaria por parte de un inversor financiero puede ocurrir, actualmente, por efecto de la comparación, en tiempo real, con papeles financieros representativos de la riqueza acumulada en otros sectores de la economía, guardando relación tenue con los fundamentos subyacentes a la actividad en cuestión (sector inmobiliario) y con su temporalidad específica (Orléan, 1999; Corpataux et al., 2009; Theurillat et al., 2015).

La percepción de un riesgo relativo mayor o de una expectativa de menor rentabilidad (relativa) lleva a los inversores a desvencijarse lo más rápido posible de un activo (en el caso que nos ocupa, una cuota de fondo) y buscar seguridad en otros títulos, ya sea en el propio país o en otros mercados. Así, a primera vista, la liquidez proporcionada por la titularidad de cuotas, reforzada por la inclinación de los gestores de fondos a componer una cartera de inmuebles sectorial y geográficamente diversificada, parece sugerir una desterritorialización del sector inmobiliario con respecto a los contextos económicos y sociales estrictamente locales. Sin embargo, como veremos, eso ocurre sólo parcialmente: las decisiones de inversión de los gestores de los fondos, amparadas en las relaciones que éstos entablan con los demás agentes de dicho circuito, limitan la profundidad de ese proceso de desterritorialización.

Para empezar, cabe discernir algunas de las razones que explican el crecimiento sustantivo en la creación de fondos de inversión inmobiliaria a partir de 2008 (gráfica 1). La primera es de naturaleza macroeconómica: por un lado, las tasas de crecimiento de la economía brasileña experimentaron una elevación considerable a partir de 2004, sobre todo en función de los estímulos provenientes del crecimiento acelerado de China y de la recuperación del rendimiento real del salario mínimo en Brasil $;{ }^{7}$ por otro, los esfuerzos emprendidos por los sucesivos gobiernos desde la década de 1990 en el sentido de favorecer el crecimiento y la consolidación del mercado de capitales en el país — desde la liberalización de la cuenta de capitales, pasando por la consolidación de un nuevo marco regulatorio,

${ }^{6}$ Desde el punto de vista de las finanzas, la lógica de minimización de riesgos vía diversificación sugiere que los fondos más atractivos serían aquellos cuya cartera de inmuebles fuera más diversificada tanto sectorialmente (inmuebles comerciales, logísticos e industriales) como territorialmente. Como veremos, por razones diversas, no es eso lo que ocurre.

${ }^{7}$ En el quinquenio de 2004 a 2008, en una coyuntura fuertemente condicionada por el escenario externo positivo, la economía creció por encima de $4 \%$ todos los años, excepto en 2005, superando notoriamente la media de crecimiento de los gobiernos de Fernando Henrique Cardoso (1995-2002). 
hasta los beneficios tributarios otorgados a las inversiones financieras (Paulani, 2008)_ crearon una oportunidad única para la emisión de fondos inmobiliarios en la Bovespa, y aquí hay que enfatizar que el sector inmobiliario fue sólo uno entre muchos de los que estrenaron o profundizaron su participación en la Bovespa desde mediados de la década del 2000.

Otras razones, de orden regulatoria y tributaria también fueron imprescindibles para el crecimiento de los fondos de inversión inmobiliaria. En 2005, las ganancias distribuidas por los fondos de inversión inmobiliaria recibieron exoneración de impuesto a la renta en la fuente. ${ }^{8}$ Esas ventajas tributarias no deben verse como una acción aislada del poder público: la discusión sobre la creación de un nuevo régimen tributario para los papeles de base inmobiliaria venía ocurriendo desde 1990, como parte del debate promovido por las instituciones financieras sobre la creación de nuevas fuentes de funding, destinadas a complementar las fuentes originarias del Sistema Financeiro de Habitação (Sistema Financiero de Vivienda) (SFH), el Sistema Brasileiro de Poupança e Empréstimo (Sistema Brasileño de Ahorro y Préstamos) (SBPE) y el Fundo de Garantia do Tempo de Serviço (Fondo de Garantía de Tiempo de Servicio) (FGTS). ${ }^{9}$ Es interesante subrayar, no obstante, que si la exoneración tributaria se justificó - en el contexto de la creación de un nuevo marco regulatorio para el financiamiento habitacional - como necesaria para atraer más inversores para los activos resultantes de hipotecas (como los CRI), y así complementar los recursos disponibles para el financiamiento inmobiliario; la extensión indebida de esa lógica a los fondos de inversión inmobiliaria -justificada según el principio constitucional de la igualdad- tiene efectos sociales y económicos diferentes, puesto que esos fondos prácticamente no invierten en el sector habitacional y, como veremos más adelante, incluso sus inversiones comerciales se concentran en edificios de lujo en algunos pocos centros urbanos brasileños.

Además de los beneficios tributarios, dos cambios regulatorios favorecieron el crecimiento de los fondos — presentado en la gráfica 1-, uno de éstos fue la instrucción de la Comissão de Valores Mobiliários (Comisión de Títulos Negociables) (CVM, no 472), que reguló más claramente la constitución, la administración, la oferta y la distribución de cuotas, así como la divulgación de informaciones por parte de nuevos fondos de inversión inmobiliaria; el otro se refiere al permiso concedido a las entidades de previsión social complementaria (los fondos de pensiones), por medio de resolución del Conselho Monetário Nacional (Consejo Mone-

\footnotetext{
${ }^{8}$ Ley no $11.196 / 05$.

${ }^{9}$ Ver Botelho (2007) y Royer (2009) para una síntesis de esas discusiones y para un mejor conocimiento de los grupos que se alinearon a favor de la creación de un sistema de financiamiento habitacional centrado en el mercado de capitales.
} 
tario Nacional) - (CMN), para que aumentaran la alícuota de su cartera invertida en el sector inmobiliario. ${ }^{10}$

\section{Gráfica 1}

Emisiones primarias de fondos de inversión inmobiliaria en Brasil

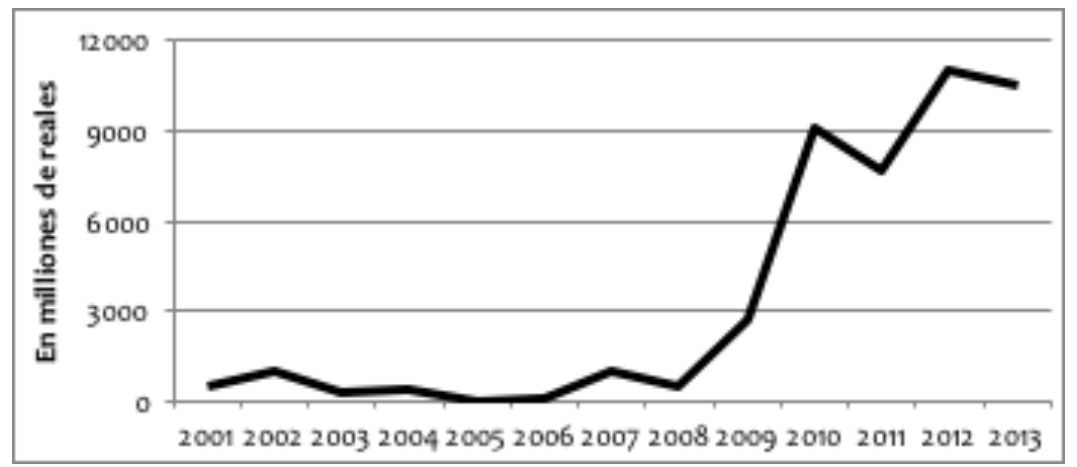

Fuente: elaboración propia con base en informaciones de la Comissão de Valores Mobiliários (2015).

Se observa, en la gráfica anterior, un crecimiento de las emisiones primarias a partir de 2009, crecimiento que refleja las nuevas regulaciones e incentivos mencionados. De un nivel inferior a R\$ 1000 millones en emisiones, durante la mayor parte de la década del 2000 hubo un salto hacia niveles superiores a los $\mathrm{R} \$ 10,000$ millones en los últimos dos años que se muestran en la gráfica. El número de fondos también creció rápidamente: había menos de 10 fondos listados en la Bolsa de Valores hasta diciembre de 2008; en 2013, esa cifra ya superaba el centenar. Si se tienen en cuenta también los fondos, cuyas cuotas se negocian en mercado mostrador, en 2014 se tienen más de 200 con patrimonio neto evaluado por encima de los R $\$ 50.000$ millones (Uqbar, 2015).

Un análisis más detenido de la trayectoria de crecimiento de los fondos inmobiliarios sugiere, no obstante, que ese crecimiento no fue tan sólo un producto de la mejora de las condiciones macroeconómicas e institucionales. En realidad, igualmente importante para ese nuevo escenario fue la agilidad con la cual una red de instituciones financieras como bancos de inversión y gestoras de activos, no muy extensa y particularmente concentrada en Sáo Paulo y Río de Janeiro, sacó provecho de las

${ }^{10}$ Lo que permitió que los fondos de pensiones aumentaran la participación en el segmento inmobiliario fue, en realidad, una nueva clasificación de los diferentes tipos de inversión para fines de contabilización en las normas que regulan la asignación de recursos. Con esta nueva regla, los fondos inmobiliarios pasaron a categorizarse como "inversiones estructuradas" y ya no como activos inmobiliarios. Eso permitió que, más allá de los límites de inversión en el sector inmobiliario que las entidades de previsión deben respetar, puedan invertir en el sector inmobiliario por medio de los fondos de inversión inmobiliaria. 
circunstancias favorables para prospectar nuevas oportunidades de inversión, crear nuevos fondos con vistas a explotar esas oportunidades y promoverlas entre sus clientes, en particular aquellos de private banking, como alternativas rentables y seguras de inversión en un contexto de disminución de intereses pagos en inversiones tradicionales como las resultantes de títulos de deuda pública (Rosa, 2011a). El éxito de la divulgación de ese vehículo fue innegable, tan es así que algunos de los entrevistados no dudan en reconocer que muchos clientes adquirieron las cuotas de nuevos fondos sin tener mucho conocimiento de los emprendimientos que darían sostén a la rentabilidad de los poseedores de cuotas. Un abogado vinculado a un despacho de abogados especializado en la prestación de servicios en el área de finanzas estructuradas es taxativo al ser indagado sobre el brote de emisiones en 2012:

Hubo mucha euforia [...], pero el mercado estaba comprando. Los intereses habían disminuido, la perspectiva de la mayor parte de los fondos era buena y sigue siéndolo, la mayoría de los fondos que salieron no eran malos, no escondían ningún fraude; lo que hubo fue un exceso de discurso en el sentido de un mejor retorno. Claro que, si el escenario seguía mejorando, se obtendría el retorno, pero era una óptica muy optimista, no había una ponderación y, entonces, por ejemplo, cualquiera podía poner el nombre del fondo de inversión inmobiliaria basura que vendía (entrevista realizada en noviembre de 2014).

Las opiniones de quienes se encuentran más directamente involucrados con la constitución, la estructuración, la distribución y la gestión de fondos de inversión inmobiliaria demuestran más mesura en el diagnóstico, en principio porque reconocer que hubo exceso de optimismo implica, tácitamente, asumir algún grado de responsabilidad de la propia empresa sobre dicho exceso. No obstante, la mayoría no niega que hubo, en el brote de emisiones de fondos, exceso de optimismo, aunque casi siempre se busque responsabilizar exclusivamente a los inversores. Un profesional de XP Investimentos, al preguntarle sobre la posibilidad de que hubiera habido excesos en la evaluación positiva de los fondos y en el número de emisiones de nuevos fondos que habrían justificado una disminución brusca de los precios en 2013, corrobora la opinión de otros entrevistados al afirmar que tiene

pocas dudas para afirmarlo. [...] Y esa disminución [de precios], en mi opinión, solo se justifica por la entrada masiva de inversores, desde pequeños inversores que compraron la idea de que las cuotas solo suben, solo suben, solo suben... y en el momento en que [el mercado] dio el primer suspiro hacia abajo, por situaciones macroeconómicas [ocurrió la disminución de precios]. Entonces, lo que justifica ese cambio tan brusco [...] de precio fue la salida masiva, o el intento de salida masiva, de esos inversores que entraron sin evaluar correctamente el fundamento [...], qué tipo de riesgo estaba implicado. [...] Si se miran las cifras, 
queda claro que una parte pequeña de la precificación es influida por las variables macroeconómicas y una parte sustancialmente grande es influida por ese movimiento de entrada y salida de inversores que [...] entraron en la puerta equivocada (entrevista realizada en mayo de 2015).

No es posible saber, con exactitud, en qué medida los bancos de inversión optaron por ignorar esas señales de optimismo injustificado para seguir estructurando y distribuyendo nuevos fondos, aunque muchos de ellos tuvieran poco que perder con la creación de fondos cuyas cuotas tuvieran probabilidad de depreciación en un futuro próximo. Es cierto que hubo, desde 2010, un escenario de recrudecimiento competitivo en el que la oferta de un nuevo fondo por una institución estructuradora estimulaba a las competidoras a crear y ofrecer un vehículo semejante, dado el escenario de absorción casi inmediata de los papeles. Ese sentimiento optimista que favorecía la absorción de los papeles por parte de los inversores también lo reforzaron consultores de inversión y notas en la prensa especializada que aconsejaban a los inversores invertir en esos fondos. En una nota de 2012, la revista Exame observa que

La euforia que hoy se ve potenciada por los altos retornos de muchos fondos. [...] En media, esas carteras tuvieron una rentabilidad anual del 30\% los últimos tres meses, mientras el Ibovespa disminuyó un 5\% y un fondo conservador de renta fija rindió un 10\% al año. Esas cifras inflaron la oferta: solo en 2012 se lanzaron 42 fondos inmobiliarios, que captaron 11.000 millones de reales. Ese tipo de fondo está ayudando a salvar el año de los bancos de inversión, que ganan un porcentaje del volumen emitido y la tasa de administración. [...] El peligro [...] es que la alta demanda de esas inversiones acabe incentivando a los gestores a lanzar fondos de forma apresurada, con inmuebles que aún tengan irregularidades, y que los inversores pongan dinero en esas carteras sin analizar adecuadamente los riesgos. Gestores, gerentes, bancos, todos están ganando con los fondos de inversión inmobiliaria. Si el inversor ganará también, es otro tema (Filgueiras, 2012).

De hecho, algunos bancos de inversión ofrecieron condiciones ficticias para atraer inversores, sobre todo por medio del instrumento de la renta mínima garantizada, que asegura al inversor una tasa de retorno mínima durante un plazo determinado (de uno a dos años, la mayoría de las veces) (Bellotto, 2012). Tras el término de ese plazo, muchas cuotas de fondo disminuyeron abruptamente, reflejando la rentabilidad real más baja (Wiltgen, 2012).

Una ilustración parcial de ese optimismo se puede observar en la gráfica 2, la cual muestra dos informaciones que permiten comparar las tendencias del mercado inmobiliario de oficinas con la evolución observada en la bolsa de valores: por un lado, está la tasa de vacancia de inmuebles comerciales en São Paulo, representada en porcentual; por otro, la gráfica registra la evolución del IFIX, un índice creado por la Bovespa en 
2011 que representa la cotización media de los fondos de inversión inmobiliaria en la bolsa. ${ }^{11}$ La gráfica 2 pone en evidencia un desplazamiento de la evolución de los precios de fondos cotizados en la bolsa con relación a las tendencias de evolución del mercado inmobiliario. Al mismo tiempo en que la tasa de vacancia subía, indicando una pérdida de dinamismo del mercado de alquileres comerciales y corporativos y, luego, un potencial deterioro en el rendimiento de las carteras de inmuebles, el índice IFIX seguía una trayectoria de ascensión muy rápida, que recién se revierte a mediados de 2013, cuando una salida masiva de inversores produce una disminución rápida de los precios de las cuotas (Cutait, 2014). En efecto, poniendo de manifiesto un periodo de descreimiento generalizado con respecto a esos activos, en muchos casos la disminución iniciada en 2013 fue tan acentuada que algunos fondos pasaron a registrar un valor de mercado (la suma del precio de las cuotas negociadas en el mercado secundario) por debajo de su valor patrimonial; en razón de eso, algunos fondos terminaron liquidándose.

\section{Gráfica 2 \\ Tasa da vacancia en el mercado corporativo de Sáo Paulo (Brasil) e índice IFIX (Bovespa)}

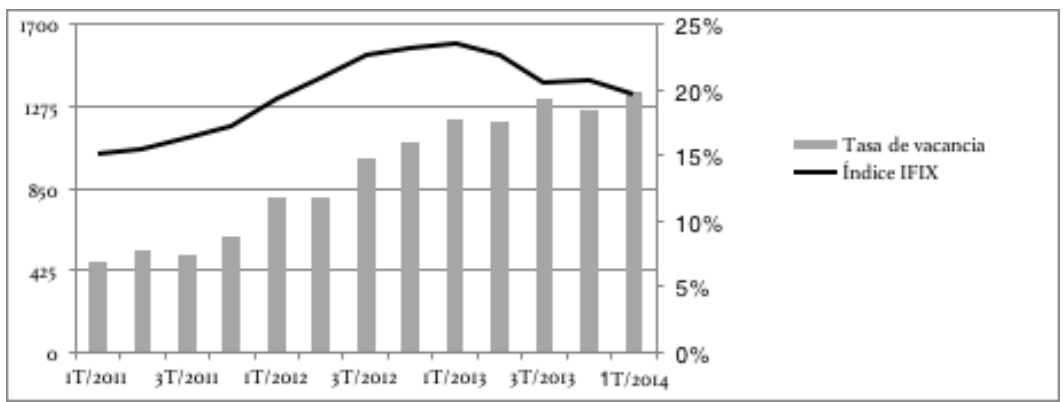

Fuentes: elaboración propia con base en informaciones contenidas de la Bolsa de Valores de São Paulo (2015) y en informes periódicos de Colliers (2015).

La gráfica 2 pone en evidencia un desplazamiento de la evolución de los precios de fondos cotizados en la bolsa con relación a las tendencias de evolución del mercado inmobiliario. $\mathrm{Al}$ mismo tiempo en que la tasa

${ }^{11}$ Se deben hacer dos salvedades en cuanto a la comparación de los dos indicadores. La tasa de vacancia captura sólo el mercado inmobiliario corporativo de São Paulo, mientras que el índice IFIX refleja el rendimiento de todos los fondos inmobiliarios, incluso de los que no invierten directamente en inmuebles, sino en otros papeles de base inmobiliaria. Esa diferencia quita robustez a la comparabilidad entre los dos índices. Por otro lado, es necesario resaltar que más de $50 \%$ de los fondos de inversión inmobiliaria tiene el mercado inmobiliario de oficinas como objetivo preferencial de inversión. De eso se desprende, entonces, que el índice IFIX reflejará, al menos en buena medida, el rendimiento de los fondos inmobiliarios con inversiones en inmuebles corporativos. 
de vacancia subía, indicando una pérdida de dinamismo del mercado de alquileres comerciales y corporativos y, luego, un potencial deterioro en el rendimiento de las carteras de inmuebles, el índice IFIX seguía una trayectoria de ascensión muy rápida, que recién se revierte a mediados de 2013, cuando una salida masiva de inversores produce una disminución rápida de los precios de las cuotas (Cutait, 2014). En efecto, poniendo de manifiesto un periodo de descreimiento generalizado con respecto a esos activos, en muchos casos la disminución iniciada en 2013 fue tan acentuada que algunos fondos pasaron a registrar un valor de mercado (la suma del precio de las cuotas negociadas en el mercado secundario) por debajo de su valor patrimonial; en razón de eso, algunos fondos terminaron liquidándose.

Aunque no estemos ante un caso más grave de burbuja de activos, en el que los efectos se propagan hacia otros sectores de la economía y en el que hay un grado elevado de empuje, no se puede ignorar que hay señales de una dinámica especulativa, característica de los mercados financieros, en la que convenciones optimistas llevan a los inversores a descuidar los riesgos de inversión y a apostar en la continuidad de la ascensión de los precios o en la elevación de la rentabilidad futura (Orléan, 1999; Froud et al., 2002; Aglietta, 2004; Coutinho y Belluzzo, 1998). Aquí se constata un paralelo con lo que sucedió en el segmento inmobiliario brasileño tras la apertura de capitales entre 2005 y 2007, cuando se formó una convención optimista que unía a los principales agentes económicos (desarrolladores, inversores, bancas de inversión, analistas, etc.) alrededor de la creencia de que la estrategia más adecuada para los desarolladores era la de crecer en volumen de oferta por medio de la diversificación regional y de segmento (Sanfelici y Halbert, 2016). Así, no resulta sorprendente que términos como fiebre y euforia no hayan sido raros en la prensa especializada al retratar retrospectivamente lo que sucedió entre 2011 y 2013. Además, se puede inferir que la demanda de los fondos de inversión inmobiliaria, de nuevos edificios corporativos a partir de 2010 contribuyó a reforzar el exceso de oferta en el segmento inmobiliario, agravado, además, por el estancamiento económico en 2014 y 2015.

\section{Las lógicas financieras y sus dinámicas regionales y urbanas}

Más allá del crecimiento del número y en el volumen del patrimonio de los fondos, viabilizado por la disposición de instituciones financieras en crear un nuevo "producto" para clientes de private banking, es posible discernir en las estrategias de inversión de los gestores de fondos de inversión inmobiliaria una orientación propia de la lógica financiera que permea las prácticas de negocios de esos agentes. Desde la perspectiva de la eco- 
nomía territorial, el desvelamiento de esas estrategias y de sus principales motivaciones es esencial porque revela la contribución de esos agentes para producir un determinado patrón de desarrollo urbano y regional cuyos efectos socioeconómicos y espaciales requieren un examen crítico.

Antes de proseguir con el análisis más minucioso de esas estrategias en su dimensión espacial, cabe exponer algunos indicadores que permiten delinear un perfil más claro de los fondos de inversión inmobiliaria en Brasil. En primer lugar, hay que resaltar que, a pesar de los incentivos creados para que las instituciones como fondos de pensiones invirtieran en fondos de inversión inmobiliaria, el perfil del inversor en fondos sigue siendo, como se mencionó anteriormente, minorista, constituido prioritariamente por individuos de ingreso alto que buscan mayor rentabilidad para sus inversiones. Del monto de cuotas de fondos emitidas en 2012, por ejemplo, $87 \%$ lo adquirieron individuos y sólo $4.6 \%$, fondos de inversión (Uqbar, 2013). Además, la participación extranjera en los fondos, aunque existente, es pequeña, en comparación, nuevamente, con lo que sucedió en el caso de las empresas de construcción y desarrollo inmobiliario tras la apertura de capital (Fix, 2011).

Un segundo indicador importante se refiere a la distribución sectorial de los activos que componen la cartera de los fondos de inversión inmobiliaria. ${ }^{12}$ Los fondos invierten, típicamente, en inmuebles que generan un flujo continuo de rentabilidad en forma de alquileres, aunque existan fondos dedicados a la participación en proyectos de desarrollo inmobiliario y a la inversión en otros papeles de base inmobiliaria (como los Certificados de Recebiveis Imobiliários, o CRI). Los fondos de renta, que son mayoritarios, ${ }^{13}$ se dividen por clases de activos. Indicadores de 2012 muestran que dos clases de activos dominan el mercado de fondos de inversión inmobiliaria, componiendo $71 \%$ del valor de capitalización del mercado: oficinas (54.2\%) y centros comerciales (17\%). El resto se divide entre activos como logística (estos en franco crecimiento), hospitales, residenciales, hotelería y alojamiento, tiendas individuales, etc. Por último, está el caso de los fondos de inversión inmobiliaria diversificados, que invierten en más de una clase de activos, con participación considerable (13.5\%).

Para comprender mejor los efectos regionales y urbanos del funcionamiento de los fondos de inversión inmobiliaria, es necesario examinar sus decisiones de inversión, así como las motivaciones y estrategias en las que se fundan esas decisiones. En el mapa 1 se presenta la distribución de los

\footnotetext{
${ }^{12}$ Estos datos se circunscriben a los fondos con cuotas listadas en la Bolsa, visto que no se ponen a disposición los datos para los demás fondos.

${ }^{13}$ Los fondos de inversión inmobiliaria que invierten exclusivamente en inmuebles constituían, en 2012, 91\% de la capitalización de todos los fondos en la Bolsa de Valores.
} 
activos controlados por fondos de inversión inmobiliaria por unidad federativa de Brasil. ${ }^{14}$ La primacía de los estados de São Paulo y Río de Janeiro en la distribución de esos activos es notoria. Es evidente que una fracción de esa concentración se debe, simplemente, al peso económico de los dos estados: en conjunto, suman casi $45 \%$ del PIB de Brasil. Sin embargo, el mapa no deja lugar a dudas en cuanto a que la concentración de los activos es de otro orden de grandeza ni de que, por lo tanto, posee fundamentos que trascienden el simple predominio económico de dichas regiones.

Las razones para esa concentración son variadas. En muchas de las entrevistas realizadas, profesionales de gestión y distribución de fondos asociaron esa concentración al deseo del inversor de conocer el inmueble físico representativo de las cuotas que posee. Un profesional entrevistado en el Banco do Brasil observa que:

la mayoría de mis clientes private que compran ese tipo de papel están concentrados [en São Paulo] y al cliente le gusta comprar un fondo de inversión inmobiliaria en un lugar que él pueda ver, aunque no sea todos los días. Por ejemplo, no hay ningún problema con el mercado inmobiliario de Palmas, pero ¿̇cuándo va el cliente a Palmas? Casi nunca, [...]. Aun cuando vendo un fondo a un cliente de Araçatuba, si el inmueble está en Río de Janeiro, él prefiere el de Río que el de Palmas, porque tiene mucho más chance de verlo [...]. Al cliente persona física le gusta ver el inmueble (entrevista realizada en septiembre de 2014).

Algunos ven en ese anhelo de estar cerca del inmueble físico un rasgo cultural brasileño, o aun ibérico, vinculado a la valorización subjetiva del inmueble como una inversión segura. Un examen más detenido del fenómeno indica, no obstante, que esa explicación de base cultural y psicológica resulta francamente insuficiente, aunque no se la pueda descartar totalmente. Basándonos en el análisis de los informes de los fondos, pero sobre todo en informaciones obtenidas (muchas veces en las entrelíneas) a partir de las entrevistas realizadas con gestores de fondos, la investigación reveló que la concentración regional de los activos de esos fondos responde, más bien, a tres fuerzas interrelacionadas que arrojan luz sobre algunos imperativos financieros subyacentes a las decisiones de gestión de los fondos inmobiliarios.

La primera es una preferencia innegable por los activos considerados prime: generalmente, oficinas corporativas de lujo, centros comerciales y centros logísticos propicios para albergar grandes empresas. La concen-

\footnotetext{
${ }^{14}$ Un activo, en este contexto, puede ser tanto un edificio entero, una unidad dentro de un edificio o una alícuota de participación en un emprendimiento, como un centro comercial. Aunque los datos se distribuyan según la unidad federativa, hay que subrayar que la mayoría de los inmuebles están ubicados en las capitales de los respectivos estados.
} 


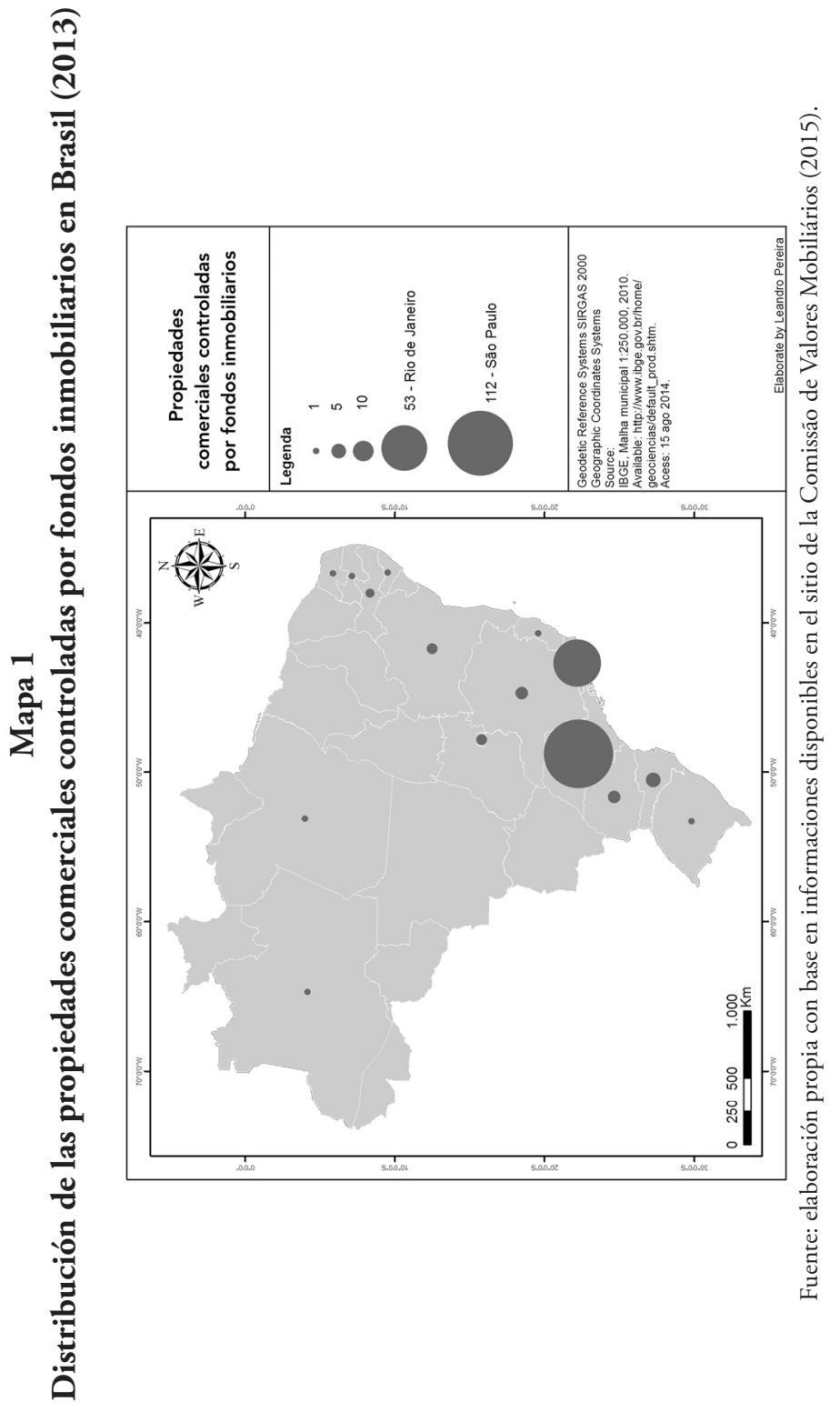


tración en esta clase de activos se explica por dos razones complementarias: por un lado, hay un deseo de reducción de costos de gestión por medio de economías de escala. Uno de los principales costos que generan los fondos inmobiliarios se refiere a la administración de los contratos de alquiler con inquilinos y otros aspectos complementarios relativos a la gestión de rutina del inmueble (manutención del inmueble, contratación de empresas tercerizadas de seguridad y portería, decisiones sobre renovación o mejoras en el aspecto de los inmuebles, etc.).

La pulverización del patrimonio del fondo impone la necesidad de administrar una multiplicidad de contratos con inquilinos de perfiles muy diferentes e inmuebles de características físicas muy diversas, lo que eleva los costos administrativos y jurídicos. Al concentrar el patrimonio en un número menor de inmuebles de superficie ${ }^{15}$ y valor unitario más elevados, se reducen proporcionalmente los costos de gestión. Por otro lado, la preferencia por inmuebles prime resulta de la búsqueda de inquilinos con un perfil determinado, que suponen, en principio, menor riesgo para el inversor (Rosa, 2011b). Ese perfil corresponde a las firmas nacionales o multinacionales de gran porte, que, al contrario de las pequeńas y medianas empresas, suelen interesarse por contratos de alquiler de largo plazo (10 o más años) (Henneberry and Mouzakis, 2014; Guironnet et al., 2016; Boisnier, 2015).

Además, por gozar de más estabilidad de flujo de caja, las grandes empresas son poco propensas a rescindir el contrato antes de su término (sea con el objetivo de expandir o de cortar costos). Esa estabilidad de los contratos de alquiler permitiría una previsibilidad mayor en el flujo de caja de los fondos de inversión inmobiliaria, dando características de una obligación (renta fija) a las cuotas de los fondos de inversión inmobiliaria. La predilección por esa clase de activos produce, en consecuencia, una concentración espacial que podríamos designar pasiva: la preferencia por Río de Janeiro y Sáo Paulo se debería al hecho de que la mayor parte de esos activos estarían previamente ubicados en esas dos ciudades. ${ }^{16}$

El segundo factor que contribuye a esa concentración regional en las dos mayores metrópolis brasileńas se relaciona igualmente con un anhelo de reducción de riesgos por medio de la búsqueda de mercados de mayor liquidez. Como ocurre en el mercado de papeles financieros, los gestores de fondos de inversión inmobiliaria procuran invertir en inmue-

${ }^{15}$ Según entrevista realizada con un gestor de fondos, los fondos prefieren adquirir pisos enteros en edificios corporativos, generalmente inmuebles de más de $1000 \mathrm{~m}^{2}$, estrategia usada también en las sociétés foncières francesas (Boisnier, 2015).

${ }^{16}$ Según datos de la consultoría Cushman and Wakefield (2014), Brasil poseía en 2014 un stock de aproximadamente 5 millones de $\mathrm{m}^{2}$ en inmuebles corporativos (sólo oficinas) clasificados como clase A. De estos, $53 \%$ estaban ubicados en São Paulo y, 26\%, en Río de Janeiro; o sea, casi $80 \%$ estaban sólo en esas dos metrópolis. 
bles ubicados en mercados más profundos, o sea, donde las operaciones de compra, venta y alquiler de inmuebles comerciales sean más frecuentes. Esa preferencia por mercados más líquidos se explica, en parte, por la mayor disponibilidad de informaciones que proporciona la liquidez: la elevada frecuencia de la compra y venta de activos prime en mercados más líquidos produce un volumen significativo de informaciones sobre la evolución de los precios y las tendencias de mercado.

En los mercados más densos, además, esas informaciones son recabadas, sistematizadas y estandarizadas por consultorías especializadas que divulgan periódicamente informes con la síntesis de la evolución de las principales variables del mercado inmobiliario comercial (precios, tasa de vacancia, nuevos inmuebles en construcción, evolución del stock total, absorción del stock, etc.). ${ }^{17}$ Esa disponibilidad de informaciones más sistemáticas favorece las decisiones de inversión de los gestores, ya sea porque les permite estimar con más rigor el precio ideal de compra o venta de un inmueble o porque facilita cálculos prospectivos de rentabilidad, basados en la estimación de los precios futuros a partir de las tendencias recientes (Crosby y Henneberry, 2016).

Más allá de ese efecto de información, la liquidez también interesa directamente en la gestión del inmueble en dos sentidos: primero, por la facilidad de reventa del activo. A pesar de que gran parte de los fondos aún no se orientan, en Brasil, por una gestión activa de su cartera (o sea, por prácticas de recomposición de cartera de conformidad con las variaciones de precio y rentabilidad de los activos), los gestores de fondos evitan mercados en los que la reventa de los activos en cartera pueda revelarse particularmente problemática debido a la escasez de compradores en potencial. En mercados menores, en los que el número de empresas aptas a ocupar un inmueble prime es reducido, la reventa del activo a otro inversor puede demorar mucho tiempo. Segundo, los fondos se preocupan por la liquidez de arrendamiento del inmueble: la probabilidad de encontrar un nuevo locatario en casos de rescisión o término de contrato aumenta cuando el inmueble en cuestión está situado en una aglomeración más grande, en la que se aglutine un número mayor de empresas de gran porte.

El tercer y último factor que explica la primacía de São Paulo y Río de Janeiro en las inversiones de los fondos de inversión inmobiliaria se refiere a las barreras que se oponen a la gestión de una cartera de activos regionalmente diversificada. A pesar de todos los avances en el sentido de una mayor integración regional e internacional de los mercados inmobiliarios (Gotham, 2006; 2009; Lizieri, 2009), el enraizamiento local de esos mer-

\footnotetext{
${ }^{17}$ Se debe resaltar que esos informes sobre el mercado inmobiliario de oficinas, elaborados por consultores como Jones Lang Lasalle, Cushman and Wakefield y Collins, entre otros, se restringen, en el caso brasileño, a las ciudades de São Paulo y Río de Janeiro.
} 
cados sigue siendo un obstáculo importante para la mayor fluidez de las inversiones de base inmobiliaria (Ball, 1983; Wood, 2004; Beauregard, 2005; Buzzelli y Harris, 2006). Esta característica no es exclusiva de los países en vías de desarrollo; más bien, se trata de una expresión de la naturaleza "espesa" (Beauregard, 2005) de los mercados inmobiliarios, enredados en configuraciones políticas, sociales, regulatorias e institucionales particulares del lugar y cuya comprensión requiere formas de conocimiento (muchas veces dichos tácitos) que se obtienen de forma privilegiada por la co-presencia.

Esas especificidades locales y regionales acaban favoreciendo una especialización geográfica de la inversión, puesto que la falta de familiaridad con relación a los mercados lejanos acaba traduciéndose, desde la perspectiva del gestor, en una percepción mayor de riesgo (Beauregard, 2005; Henneberry y Mouzakis, 2014). En el caso de los fondos inmobiliarios, esa prioridad concedida al lugar adquiere expresión en la dinámica de prospección de nuevos negocios: la participación de los gestores de fondos en círculos cotidianos de interacción profesional con emprendedores del segmento inmobiliario local (Sáo Paulo o Río de Janeiro) y empresas inclinadas a la venta de su patrimonio inmobiliario funciona como un canal privilegiado de información sobre nuevas oportunidades en la ciudad con buen potencial de retorno que disminuye el tiempo y el costo de prospección. ${ }^{18}$

Todas esas características hacen la inversión fuera de la región menos atractiva, por exigir la movilización de profesionales especializados en otros mercados y la apertura de oficinas regionales, costos que pueden no ser compensados por el volumen de negocios. Es interesante subrayar, que si por un lado la creación de nuevos activos financieros con base inmobiliaria consiste en una forma de desterritorialización del activo inmobiliario, cuyas ganancias pueden ahora circular más libremente en las manos de inversores distantes, por otra parte, la diversificación (regional) de la cartera de activos sigue siendo trabada por el enraizamiento territorial de los agentes financieros y por el flujo de información generado por su interacción con emprendedores inmobiliarios y firmas locales.

Si la diversificación geográfica es limitada a escala regional, también hay un sesgo no cuestionado a escala urbana a favor de las áreas más valorizadas o con mayor potencial de valorización futura. Lo que explica tal sesgo a escala urbana, en parte, radica en la primera razón que

\footnotetext{
${ }^{18}$ Esta conclusión permite realizar una analogía con los resultados de la investigación de Wójcik (2011), que demuestra que las firmas ubicadas en centros financieros son más propensas a la apertura de capital que aquellas situadas en otras aglomeraciones, justamente en virtud de la proximidad de esas empresas con respecto a un pool de profesionales de las finanzas que facilitan la emisión de títulos privados.
} 
explica igualmente la asimetría de las inversiones a escala regional: la prioridad concedida a los inmuebles prime acaba encaminando las inversiones hacia los distritos de negocios de las ciudades en los que está ubicada la mayoría de esos inmuebles. Sin embargo, más allá de esa actitud meramente pasiva en la elección de las inversiones, es posible conjeturar que algunos gestores de fondos trabajan activamente en el sentido de invertir en áreas de la metrópolis con gran potencial de valorización futura. Esa postura es coherente con la estrategia elemental de la mayor parte de los fondos de inversión inmobiliaria de adquirir inmuebles para obtener un flujo de rentabilidad a mediano y largo plazo: al invertir recursos en un inmueble ubicado en una zona en curso de valorización se minimiza el riesgo de que el flujo de ganancias futuras esperadas no se haga efectivo. Al mismo tiempo, considerando que los fondos más activos ejecutan estrategias de recomposición de la cartera de inmuebles - compra y venta de activos inmobiliarios basadas en cálculos financieros de flujos de rentabilidad y ganancias de capital— la adquisición de un inmueble en un área con tendencia a la valorización amplía las posibilidades de ganancias de capital en esas transacciones.

Las repercusiones territoriales de esas decisiones de inversión se pueden verificar en el mapa 2, en el cual se muestran los inmuebles comerciales de propiedad de fondos de inversión inmobiliaria en São Paulo, ${ }^{19}$ espacio en el que los inmuebles están situados, mayoritariamente, en la región que la alcaldía de la ciudad llama centro expandido y que comprende el centro histórico y un conjunto de distritos cercanos en los que hay mayor densidad de ocupación del suelo.

Sin embargo, en el interior de esa área, los gestores priorizan algunos distritos, sobre todo los de Pinheiros (VII en el mapa) y Itaim Bibi (XIV). Ese último es actualmente el núcleo más valorizado del eje de negocios de la capital paulista y concentra las actividades financieras más avanzadas (bancos de inversión, gestores de activos, evaluadoras de crédito, entre otros.), una gama de servicios complementarios (asistencia jurídica, consultorías, aseguradoras, etcétera.), además de las sedes de grandes empresas del ramo industrial y comercial. También en ese distrito se ubican las principales firmas de gestión de activos, bancos y asesores jurídicos que organizan el mercado de fondos de inversión inmobiliaria, así como los desarrolladores que construyen los inmuebles comerciales que adquieren los fondos inmobiliarios.

Es interesante registrar, también, que una de las áreas que viene captando inversiones de los fondos de inversión inmobiliaria es el distrito de

\footnotetext{
${ }^{19}$ A diferencia del mapa anterior, en el que se representaron los activos inmobiliarios de todos los fondos de inversión inmobiliaria listados, en el mapa 4 están representados sólo los inmuebles de oficinas, que son el objeto central de este estudio.
} 


\section{Mapa 2 \\ Inmuebles comerciales en manos de fondos de inversión inmobiliaria en Sáo Paulo (Brasil, 2013)*}

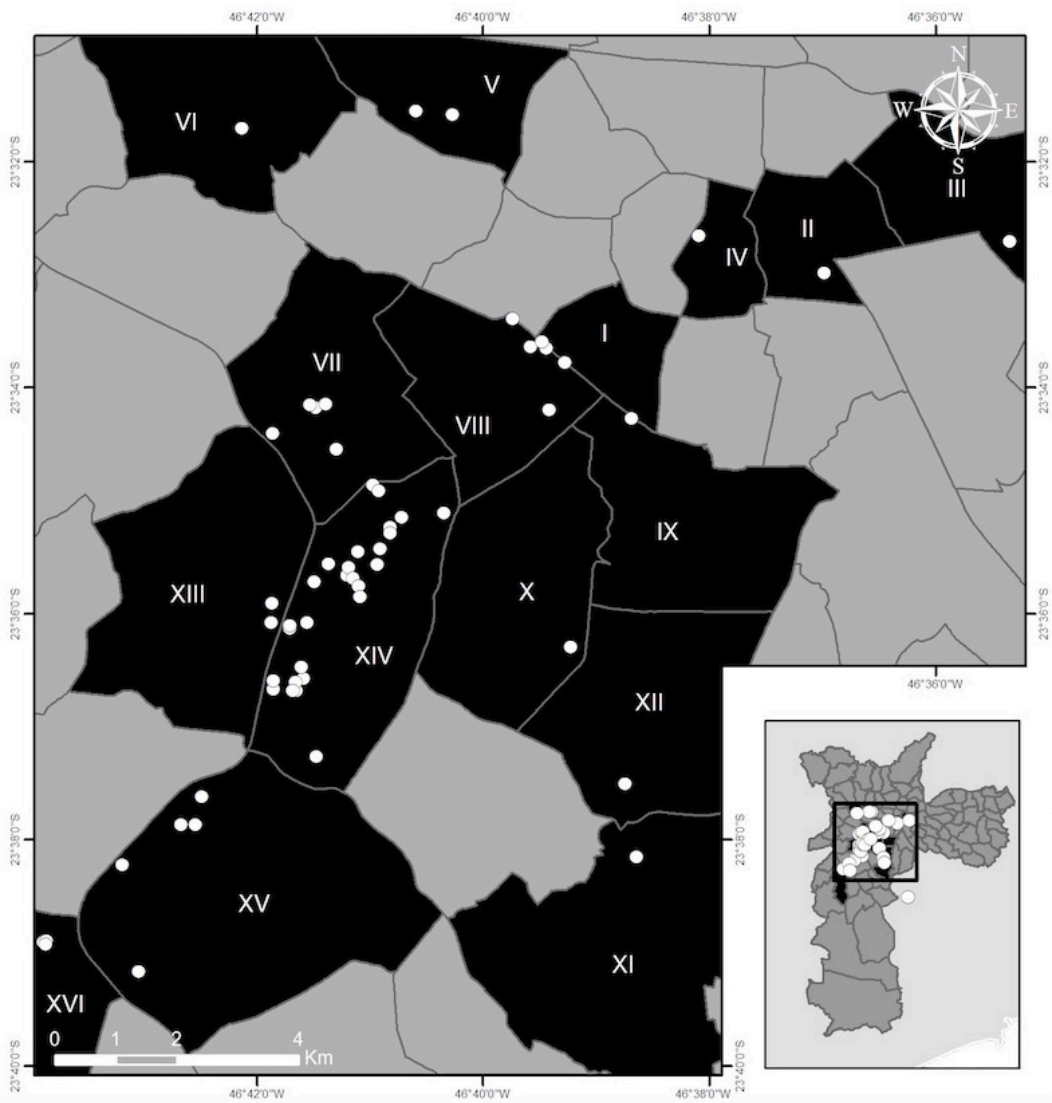

* El mapa representa sólo oficinas. Cada punto corresponde a una propriedad. Los distritos representados en el mapa son: I. Bela Vista; II.Brás; III. Belém; IV. Sé; V. Barra Funda; VI. Lapa; VII. Pi-nheiros; VIII. Jardim Paulista; IX. Vila Mariana; X. Moema; XI. Jabaquara; XII. Saúde; XIII. Mo-rumbi; XIV. Itaim Bibi; XV. Santo Amaro y XVI. Jardim São Luís.

Fuente: elaboración propia con base en informes periódicos de los administradores de fondos de inversión inmobiliaria.

Santo Amaro XV, en el mapa 2. Aún constituído predominantemente de casas de dos plantas y pequeños comercios, Santo Amaro está consagrándose como la nueva frontera de expansión del eje de negocios de São Paulo, sobre todo tras el éxito de la Operação Urbana Água Espraiada (Operación Urbana Água Espraiada), una intervención urbana basada en el principio de recuperación de plusvalías inmobiliarias por medio de la venta de potencial adicional de construcción. La operación ha rendido a la alcaldía más de cinco mil millones de reales (dos mil millones de 
dólares), recursos que sólo pueden aplicarse dentro del perímetro de intervención. Esa exigencia de aplicación de los recursos funciona como una especie de garantía de valorización futura, atrayendo más inversiones inmobiliarias hacia el área, en esta operación, además, sólo 60\% de los recursos recaudados por la alcaldía se habían invertido (Infomoney, 2015), lo que sugiere que nuevas mejoras futuras deberán consolidar la región como eje de negocios. Ahora bien, eso explica el interés de los fondos de inversión inmobiliaria.

En conclusión, los fondos de inversión inmobiliaria contribuyen a consolidar y expandir el eje valorizado de la metrópolis e, indirectamente, a desplazar las actividades económicas de menor valor agregado, así como a grupos sociales de ingresos más bajos hacia distritos más periféricos. Sus inversiones se concentran en la capa superior del stock de edificios comerciales de São Paulo, en virtud sobre todo del intento de minimizar costos relacionados con la pulverización de los contratos de alquiler y atenuar los riesgos vinculados a locatarios, a los cuales se les atribuye menor credibilidad.

\section{Conclusión}

En este artículo se procura elucidar las fuerzas y procesos que contribuyeron al surgimiento y consolidación de los fondos de inversión inmobiliaria; como instrumentos de inversión colectiva en Brasil, así como analizar y explicar el perfil de inversión de dichos vehículos desde un punto de vista territorial. Dos conclusiones sobresalen de esta investigación: en primer lugar, aunque una serie de cambios regulatorios hayan viabilizado el vehículo como alternativa de inversión después de 2009, conviene resaltar el protagonismo de un conjunto de instituciones financieras en el origen y la distribución de nuevos fondos de inversión inmobiliaria entre sus clientes bancarios, básicamente, individuos de ingresos elevados. Esa colaboración estrecha entre un grupo de instituciones financieras y agentes como consultores de inversión y analistas permitió una difusión rápida de los fondos y, entre 2012 y 2013, un frenesí de nuevas emisiones, basado en una percepción colectiva excesivamente optimista con relación a la rentabilidad futura de las inversiones. La segunda conclusión apunta a una neta tendencia a la concentración de los activos controlados por fondos de inversión inmobiliaria, tanto a escala regional como a escala urbana, lo que sugiere que el vehículo refuerza un patrón de desarrollo territorial desigual. Como se ha mostrado anteriormente, esas estrategias de inversión reflejan las percepciones, exigencias y expectativas que unifican el mercado financiero en torno a nociones particulares de riesgo y rentabilidad. En particular, destacan a preferencia de los gestores por la 
liquidez de los activos inmobiliarios; la búsqueda de una rentabilidad más elevada por medio de economías de escala con la reducción en el número de contratos (e inmuebles) administrados; y el esfuerzo por reducir riesgos de alquiler priorizando empresas de mayor credibilidad.

Los resultados de la investigación suscitan algunas cuestiones de orden político cuyo planteamiento se impone, sobre todo ante las justificativas que movilizan los agentes financieros y sus organizaciones en pro del perfeccionamiento del marco regulatorio y de la permanencia de los incentivos tributarios otorgados a los fondos. Como se ha señalado, los fondos concentran la mayor parte de sus actividades en las dos mayores metrópolis brasileñas y, en el interior de esas ciudades, en un perímetro bastante limitado del espacio urbano, como reflejo de las expectativas que circulan en los mercados financieros. Como instrumento para financiar empresas que buscan movilizar patrimonio inmovilizado (o sea, vender sus activos inmobiliarios) a fin de concentrar recursos en su negocio principal; los fondos de inversión inmobiliaria favorecen prioritariamente las empresas de mayor porte, ya beneficiadas por un acceso más amplio a diferentes modalidades de crédito. No disponen del mismo beneficio ni las empresas menores que necesitan recursos para consolidarse ni las empresas consolidadas cuyas bases no se sitúan en las mayores metrópolis.

En lo que atañe al desarrollo urbano, los fondos constituyen una demanda adicional para la construcción de edificios corporativos en los distritos más valorizados o con potencial mayor de valorización, contribuyendo a desplazar los demás usos del suelo no compatibles con la expectativa de rentabilidad de los propietarios inmobiliarios. Esos efectos concentradores se hacen efectivos en el contexto de un marco regulatorio en el que las ganancias distribuidas por los fondos de inversión inmobiliaria entre los inversores (la mayoría de rentabilidad elevada) son exonerados del impuesto a la renta, reforzando la conocida regresividad del sistema tributario brasileño (Gondim y Lettieri, 2010). Hay, por ende, un doble efecto de concentración en el diseńo y operación de los fondos de inversión inmobiliaria como vehículos de inversión: por una parte, la exoneración tributaria beneficia a los estratos de ingresos más elevados; por otra, como instrumento de financiamiento urbano, los fondos refuerzan patrones de desarrollo urbano y regional asimétricos.

Por último, en el plano teórico, la investigación abre posibilidades para pensar la financiarización (de la ciudad) como resultado de prácticas cotidianas de intermediación, inversión e innovación de una red territorializada de agentes financieros — como bancos de inversión, firmas de asset management, departamentos de private banking, fondos de titulización, agencias de calificación de riesgos, etc.- - que se encuentran en la delantera del proceso de securitización de los activos inmobiliarios. Esos agentes 
comparten con inversores un ambiente común (y cotidiano) de negocios en el seno del cual se fabrican nuevos activos financiero-inmobiliarios y se construyen colectivamente las nociones (bastante particulares) de riesgo y rentabilidad que permean la circulación de dichos papeles. A medida que avanza la financiarización en el segmento inmobiliario, cada vez más esas formas particulares de concebir el riesgo y la rentabilidad se imponen sobre concepciones alternativas existentes, produciendo efectos sobre la geografía de las ciudades y las regiones.

\section{Agradecimientos}

Este artículo es resultado de la investigación de postdoctorado realizada en la Universidad Federal Fluminense (2014) y en la Universidad Paris-Est (2015). Agradecemos a Capes por el financiamiento de dicha investigación. Traducido del portugués por Adriana Carina Camacho Álvarez.

\section{Fuentes consultadas}

Aalbers, Manuel (2008), "The financialization of home and the mortgage market crisis", Competition \& change, 12 (2), Sage Publishing, Londres, Reino Unido, pp. 148-166.

Aglietta, Michel (2004), Macroeconomia financeira I: mercado financeiro, crescimento e ciclos, Ediçóes Loyola, São Paulo, Brasil.

Ball, Michael (1983), Housing policy and economic power, Routledge, Londres, Reino Unido.

Bellotto, Alessandra (2012), "Cuidado com a euforia do fundo imobiliário", Valor Econômico, <http://www.valor.com.br/financas/2938178/cuidado-com-euforia-do-fundo-imobiliario $>, 28 \mathrm{de}$ febrero de 2017.

Bellotto, Alessandra y Luciana Monteiro (2010), "Overdose de fundos imobiliários?”, Valor Econômico, <http://www.valor.com.br/arquivo/844553/overdose-de-fundos-imobiliarios>, 28 de febrero de 2017.

Beauregard, Robert (2005), "The textures of property markets: downtown housing and office conversions in New York City", Urban Studies, 42 (13), Sage Publishing, Londres, Reino Unido, pp. 2431-2445. 
Boisnier, Cyril (2015), Les sociétés foncières: entre finance et ville durable, L'Harmattan, Paris, Francia.

Botelho, Adriano (2007), O urbano em fragmentos, Annablume, São Paulo, Brasil.

Bovespa (Bolsa de Valores de São Paulo) (2015), “Índice IFIX”, Bovespa, Sáo Paulo, Brasil <www.bmfbovespa.com.br>, 4 de abril de 2017.

Buzzelli, Michael y Richard Harris (2006), "Cities as the industrial districts of housebuilding", International Journal of Urban and Regional Research, 30 (4), Wiley, Londres, Reino Unido, pp. 894-917.

Cattaneo-Pineda, Rodrigo (2011), "Los fondos de inversión inmobiliaria y la producción privada de vivienda en Santiago de Chile: ¿Un nuevo paso hacia la financiarización de la ciudad?", EURE (Santiago), 37 (112), Pontificia Universidad Católica, Santiago, Chile, pp. 5-22.

Chesnais, François (2002), "A teoria do regime de acumulação financeirizado: conteúdo, alcance e interrogaçóes", Economia e Sociedade, 11 (1), Unicamp, Campinas, Brasil, pp. 1-44.

Coakley, James (1994), "The integration of property and financial markets”, Environment and planning A, 26 (5), Sage Journals, Londres, Reino Unido, pp. 697-713.

Corpataux, Jose, Olivier Crevoisier y Thierry Theurillat (2009), "The expansion of the finance industry and its impact on the economy: a territorial approach based on Swiss pension funds", Economic Geography, 85 (3), Wiley, Londres, Reino Unido, pp. 313-334.

Coutinho, Luciano y Luiz Gonzaga Belluzzo (1998), "Financeirização da riqueza, inflação de ativos e decisões de gasto em economias abertas", Economia e Sociedade, 7 (2), Unicamp, Campinas, Brasil, pp. 137-150.

Colliers (2015), "Relatório de Mercado-Brasil", Colliers, São Paulo, Brasil, <www.colliers.com/pt br/brazil/insights/reports/saopaulo>, 4 de abril de 2017.

Crosby, Neil y John Henneberry (2016), "Financialisation, the valuation of investment property and the urban built environment in the 
UK", Urban Studies, 53 (7), Sage Journals, Londres, Reino Unido, pp. 1424-1441.

CVM (Comissão de Valores Mobiliários) (2015), "Fundos imobiliários", CVM, Rio de Janeiro, Brasil, <www.cvm.org.br>, 4 de abril de 2017.

Cushman and Wakefield (2014), Marketbeat office snapshot: Brasil, Cushman \& Wakefield Research, São Paulo, Brasil.

Cutait, Beatriz (2014), "Fundo imobiliário: em reconstrução", Valor Econômico, <http://www.valor.com.br/financas/3577814/fundoimobiliario-em-reconstrucao >, 28 de febrero de 2014.

David, Louise y Ludovic Halbert (2014), "Finance capital, actor-network theory and the struggle over calculative agencies in the business property markets of Mexico City Metropolitan Region”, Regional Studies, 48 (3), Taylor \& Francis, Londres, Reino Unido, pp. 516-529.

Filgueiras, Maria Luiza (2012), "Viu o oba-oba dos fundos imobiliários?”, Revista Exame, <http://exame.abril.com.br/revista-exame/edicoes/1031/noticias/o-oba-oba-dos-fundos $>, 28$ de febrero de 2017.

Fix, Mariana (2011), "Financeirização e transformações recentes no circuito imobiliário no Brasil", tesis de doctorado, Instituto de Economia, Unicamp, Campinas, Brasil.

Froud, Julie, Sukhdev Johal y Karel Williams (2002), "Financialisation and the coupon pool”, Capital \& Class, 26 (3), Sage Journals, Londres, Reino Unido, pp. 119-151.

Gondim, Fátima y Marcelo Lettieri (2010), “Tributação e desigualdade", Le Monde Diplomatique Brasil, <http://diplomatique.org.br/ tributacao-e-desigualdade/>, 28 de febrero de 2017.

Gotham, Kevin Fox (2009), "Creating liquidity out of spatial fixity: the secondary circuit of capital and the subprime mortgage crisis", International Journal of Urban and Regional Research, 33 (2), Wiley, Londres, Reino Unido, pp. 355-371. 
Gotham, Kevin Fox (2006), "The secondary circuit of capital reconsidered: globalization and the US real estate sector", American Journal of Sociology, 112 (1), University of Chicago, Chicago, Estados Unidos, pp. 231-275.

Guironnet, Antoine, Katia Attuyer y Ludovic Halbert (2016), "Building cities on financial assets: the financialisation of property markets and its implications for city governments in the Paris city-region”, Urban Studies, 53 (7), Sage Journals, Londres, Reino Unido, pp. 1442-1464.

Halbert, Ludovic y Hortense Rouanet (2014), "Filtering risk away: global finance capital, transcalar territorial networks and the (un) making of city-regions: an analysis of business property development in Bangalore, India”, Regional Studies, 48 (3), Taylor \& Francis, Londres, Reino Unido, pp. 471-484.

Halbert, Ludovic, John Henneberry y Francis Mouzakis (2014), "The Financialization of Business Property and What It Means for Cities and Regions", Regional Studies, 48 (3), Taylor \& Francis, Londres, Reino Unido, pp. 547-550.

Harvey, David (1999), The limits to capital, Verso, 2nd, New York, Estados Unidos.

Henneberry, John and Francis Mouzakis (2014), "Familiarity and the determination of yields for regional office property investments in the UK”, Regional Studies, 48 (3), Taylor \& Francis, Londres, Reino Unido, pp. 530-546.

Infomoney (2015), "Recursos oriundos de boom imobiliário ficam presos nos bancos", Infomoney, <http:/www.infomoney.com.br/imoveis/ noticia/3787714/recursos-oriundos-boom-imobiliario-ficampresos-nos-bancos>, 28 de febrero de 2017.

Lapavitsas, Costas (2009), "Financialised capitalism: Crisis and financial expropriation", Historical Materialism, 17 (2), The School of Oriental and African Studies, University of London, Londres, Reino Unido, pp. 114-148.

Leyshon, Andrew y Nigel Thrift (2007), "The capitalization of almost everything: the future of finance and capitalism", Theory, Cul- 
ture \& Society, 24 (7-8), Sage Journals, Londres, Reino Unido, pp. 97-115.

Lizieri, Colin (2009), Towers of capital, Wiley-Blackwell, Oxford, Reino Unido.

Newman, Kathe (2009), "Post-Industrial Widgets: Capital Flows and the Production of the Urban", International Journal of Urban and Regional Research, 33 (2), Wiley, Londres, Reino Unido, pp. 314-331.

Orléan, Andre (1999), Le pouvoir de la finance, Odile Jacob, París, Francia.

Paulani, Leda (2008), Brasil delivery, Boitempo, São Paulo, Brasil.

Plihon, Dominique (2010), Le nouveau capitalisme, La Découverte, París, Francia.

Renard, Vincent (2008), "La ville saisie par la finance”, Le Débat, (48), Gallimard, París, Francia, pp. 106-117.

Rolnik, Raquel (2013), "Late neoliberalism: the financialization of homeownership and housing rights", International Journal of Urban and Regional Research, 37(3), Wiley, Londres, Reino Unido, pp. 1058-1066.

Rosa, Silvia (2011a), "XP monta estrutura para originar fundos imobiliários", Valor Econômico, <http://www.valor.com.br/financas/999084/xp-monta-estrutura-para-originar-fundos-imobiliarios>, 28 de febrero de 2017.

Rosa, Silvia (2011b), "Concentração em um único inquilino eleva risco da carteira”, Valor Econômico, <http://www.valor.com.br/impresso/financas-e-investimentos/concentracao-em-um-unico-inquilino-eleva-risco-da-carteira>, 28 de febrero de 2017.

Royer, Luciana (2009), "Financeirização da política habitacional: limites e perspectivas", tesis de doctorado, Faculdade de Arquitetura e Urbanismo, Universidade de São Paulo, São Paulo, Brasil.

Sanfelici, Daniel y Halbert, Ludovic (2016), "Financial markets, developers and the geographies of housing in Brazil: A supply-side ac- 
count", Urban Studies, 53 (7), Sage Journals, Londres, Reino Unido, 1465-1485.

Sanfelici, Daniel (2013a), "Financeirização e a produção do espaço urbano no Brasil: uma contribuição ao debate", EURE (Santiago), 39 (118), Pontificia Universidad Católica, Santiago, Chile, pp. 27-46.

Sanfelici, Daniel (2013b), "A metrópole sob o ritmo das finanças: implicaçôes socioespaciais da expansão imobiliária no Brasil”, tesis de doctorado, Faculdade de Filosofia, Letras e Ciências Humanas, Universidade de São Paulo, São Paulo, Brasil.

Shimbo, Lúcia (2012), Habitação social de mercado, Editora C/Arte, Belo Horizonte, Brasil.

Sotelo, Ramón y Stanley McGreal (2013), Real estate investment trusts in Europe, Springer, Nueva York, Estados Unidos.

Theurillat, Thierry, Patrick Rérat and Olivier Crevoisier (2015), “The real estate markets: players, institutions and territories", Urban Studies, 52 (8), Sage Journals, Londres, Reino Unido, pp. 1414-1433.

Theurillat, Thierry, Jose Corpataux y Olivier Crevoisier (2010), "Property sector financialization: the case of Swiss pension funds (19922005)", European Planning Studies, 18 (2), Taylor \& Francis, Londres, Reino Unido, pp. 189-212.

Uqbar (2015), Securitização e financiamento imobiliário, Uqbar, Rio de Janeiro, Brasil.

Uqbar (2013), Guia Do Investidor: Fundos Imobiliários, Uqbar, Rio de Janeiro, Brasil.

Weber, Rachel (2010), "Selling city futures: the financialization of urban redevelopment policy”, Economic Geography, 86 (3), Wiley, Londres, Reino Unido, pp. 251-274.

Wiltgen, Julia (2012), "Maior problema de fundo imobiliário é imóvel mal avaliado", Revista Exame, <http://exame.abril.com.br/seudinheiro/maior-problema-de-fundo-imobiliario-e-imovel-malavaliado/>, 28 de febrebro de 2017. 
Wójcik, Dariusz (2011), "Securitization and its footprint: the rise of the US securities industry centres 1998-2007”, Journal of Economic Geography, 11 (6), Oxford Academic, Oxford, Reino Unido, pp. 925-947.

Wood, Andrew (2004), "The Scalar Transformation of the US Commercial Property-Development Industry: A Cautionary Note on the Limits of Globalization", Economic Geography, 80 (2), Wiley, Londres, Reino Unido, pp. 119-140.

Recibido: 17 de julio de 2015. Corregido: 23 de diciembre de 2016. Aceptado: 23 de febrero de 2017.

Daniel Sanfelici. Doctor en geografía humana por la Universidad de São Paulo, Brasil. Actualmente es profesor-investigador del Departamento de Geografía en la Universidad Federal Fluminense, Brasil. Entre sus últimas publicaciones destacan: "A centralidade das aglomeraçóes metropolitanas na economia globalizada: fundamentos econômicos e possibilidades políticas", Cadernos Metrópole, 18 (37), Observatório das Metrópoles, Rio de Janeiro, pp. 623-646 (2016); en coautoría, "Financial markets, developers, and the geographies of housing in Brazil: a supply-side account", Urban Studies, 53 (7), Urban Studies Journal Limited, Sage Publications, pp. 1-21 (2016). 